\title{
Santiago: a solidão sob o prisma do filme-ensaio
}

\author{
Rafael de Almeida' \\ Paulo Passos de Oliveira" \\ I - Universidade Estadual de Goiás \\ Goiânia (GO), Brasil \\ II - UFGO \\ Goiânia (GO), Brasil
}

Resumo: O presente artigo propõe uma reflexão em torno da relação entre o filme-ensaio e a solidão, à luz de Santiago (João Moreira Salles, 2007). Objetiva-se investigar de que forma o caráter ensaístico da obra interfere na maneira em que a solidão do protagonista Santiago nos é apresentada. Partimos da hipótese de que o filme assume uma certa ambiguidade reflexiva sobre tal aspecto, apresentando assim uma dupla possibilidade: ora Santiago parece estar só, como um desejo voluntário do personagem; ora assemelha ser solitário, consequência de um processo de exclusão social explicitada pela relação que mantém com o diretor do filme. Pretendemos analisar Santiago com foco na problemática exposta, para propor que tal ambiguidade vivenciada pelo protagonista, entre estar só e ser solitário, é também condição essencial para que o ensaísta audiovisual assuma a distância reflexiva necessária para desenvolver sua narrativa.

Palavras-chave: filme-ensaio; solidão; Santiago (filme).

Abstract: Santiago: loneliness under the perspective of the essay film. The present article proposes a reflection on the relation between the essay film and loneliness, in the light of Santiago (João Moreira Salles, 2007). The objective is to investigate how the essayistic nature of the work interferes with the way in which the loneliness of the protagonist Santiago is presented to us. We start from the hypothesis that the film assumes a certain reflexive ambiguity about this aspect, presenting a dual possibility: sometimes Santiago seems to be alone, as a willful desire of the character; sometimes appears lonely, as a result of a process of social exclusion explained by the relationship that he maintains with the director of the film. We intend to analyze Santiago focusing on such a problem, to propose that the ambiguity experienced by the protagonist, between being alone and being lonely, is also an essential condition for the audiovisual essayist to maintain the reflexive distance necessary to develop his narrative.

Keywords: essay film ; loneliness; Santiago (film). 


\section{Introdução}

Santiago (João Moreira Salles, 2007) foi vencedor de vários prêmios no Brasil e no exterior, tendo sido eleito pela Associação Brasileira de Críticos de Cinema (Abraccine), em 2015, como um dos 100 melhores filmes brasileiros de todos os tempos. O longa-metragem apresenta-nos o personagem Santiago Badariotti Merlo (1912-1994), mordomo da família Moreira Salles. Aposentado, o argentino de origem italiana, erudito e poliglota, vivia só em um pequeno apartamento no bairro do Leblon, no Rio de Janeiro, entre memórias e milhares de textos que escrevia sobre a história de nobres de todo o mundo. Embora o filme de João Moreira Salles tenha recebido certa fortuna crítica, justifica-se que pouco foi discutido com o recorte aqui proposto.

A partir de Santiago, pretendemos refletir acerca da solidão sob o prisma do filmeensaio. Considerando o encontro promovido pela obra desses dois elementos, o problema de pesquisa a que nos dedicamos questiona quais são os desdobramentos do caráter ensaístico da obra sobre a forma que a solidão do protagonista Santiago nos é dada a ver.

Trabalhamos com a hipótese de que a solidão de Santiago nos é apresentada por meio de certa ambiguidade reflexiva característica dos filmes-ensaio. Por um lado, o filme parece sugerir que ele se entregou voluntariosamente à solidão, como fruto de um querer, no que podemos definir como ato de estar só. Por outro lado, a obra aponta para outra possibilidade, de uma solidão indesejada que afasta o sujeito de toda a conjuntura contemporânea, que o coloca na condição de marginalidade, por nós designado como ato de ser solitário.

Para analisar a obra será realizada uma investigação formal e temática de determinadas cenas, em que a solidão do personagem se faz predominante, interessada em compreender os procedimentos do filme-ensaio utilizados e como eles impactam na maneira como percebemos Santiago: como alguém que deseja estar só ou se reconhece como um ser solitário. A partir disso estaremos habilitados a ponderar acerca das reverberações dessa condição solitária em outras instâncias enunciativas, como o diretor.

Pretendemos em um primeiro momento discutir sobre a maneira como o personagem Santiago é construído sob a ótica da solidão, para, logo em seguida, pensar sobre as contribuições que o caráter de filme-ensaio da obra trazem à percepção que temos desse sentimento comungado pelo protagonista, na condição de espectadores. Com esse panorama em vista, temos interesse de analisar a solidão presente em Santiago enquanto um sentimento perceptível, uma característica fluida do personagem, mas também uma condição que define aspectos necessários à realização. Dessa forma, nesse ponto, pretendemos ser capazes de propor que tal ambiguidade vivenciada pelo protagonista, entre estar só e ser solitário, é também condição primordial para que o ensaísta audiovisual adote a distância reflexiva tão cara ao filme-ensaio. 


\section{O personagem Santiago: entre estar só e ser solitário}

Por volta dos 20 minutos de duração do filme, vemos Santiago sentar-se ao lado de uma pequena estante repleta de papeis cuidadosamente empilhados e dispostos, na sala de seu apartamento. Logo em seguida ele parece dizer algo que não ouvimos, simultaneamente ao gesto de delicadamente acariciar e apresentar as resmas à equipe que está fora de quadro, como quem exibe um tesouro. E enquanto o vemos, ouvimos a voz-over ensaística dizer: "Santiago não estava acostumado a receber pessoas no seu apartamento. Quando chegamos, ele entregou a cada um de nós um guardanapo embebido em álcool e cânfora para que limpássemos as mãos. Ele vivia só, cercado de seus livros: a história dos Médices, a biografia de Lucrécia Bórgia, e da obra de toda sua vida. Trinta mil páginas transcritas em bibliotecas públicas e particulares, espalhadas por três continentes".

Santiago afirma que para ele seus personagens históricos não estão mortos. Em sua fala, que mistura português e espanhol, nos esclarece que todos o fazem companhia. Sendo assim, nossa primeira interpretação de Santiago parte de que o personagem Santiago não deve ser visto como um solitário, mas como alguém que optou por estar só, entre seus livros e textos. Machado Pais (2006) nos informa que estar só não é ser solitário. Estar só pressupõe uma opção deliberada do agente isolado. A solidão é relegada por algo ou alguém a outro alguém, e o isolado, na maioria dos casos, não tem gerência sobre sua condição. O solitário, aqui posto, é alguém que não deseja a condição.

Mais adiante, toca o relógio de parede da sala, justo acima da estante em que descansa toda a nobreza do mundo. Santiago, sentado abaixo do relógio e ao lado da estante, aponta para ele e diz: “Este som, este relógio de mais de cem anos, ele dá vida, conserva, os conserva vivos e frescos para mim. Ele, com suas badaladas, dáIhes vida". Apontando e tocando com as mãos os textos escritos sobre os nobres, nos informa que eles dormem aos pés de sua cama. "Uma vez por semana eu converso com eles, os ventilo, passeio com eles, passeio com eles pelo apartamento. Eu moro completamente só, mas eu não estou só porque estou rodeado por essa gente".

$\mathrm{O}$ ato de escrever, e a relação que Santiago manifesta possuir com seus personagens históricos, transforma-se em um refúgio, um espaço interior, lugar de elaboração de questões pessoais. Suas narrativas resgatadas de livros de história, e reescritas a partir de critérios muito particulares, levam Santiago a um estado próprio de consciência, nisso que podemos definir como seu "estar no mundo". Neste sentido, no filme de João Moreira Salles, a solidão do protagonista é manifestada em sua dimensão positiva em um primeiro instante. 


\begin{abstract}
Sim, esta é a dimensão positiva da solidão, condição básica de nossa existência, que faz com que nos desviemos da preocupação estressante com o lado de fora, com o mundo que nos envolve, provoca e oprime - apesar de nos atrair e fascinar - para a preocupação com o lado de dentro de nós mesmos. É que nos gastamos quando buscamos saber das coisas que nos rodeiam e, de repente, nos vemos confrontados com o desafio de nosso próprio mundo interior. Os pensadores dizem que este desvio é uma fundamental passagem de um estado de ciência para um estado de consciência, sinal manifestador de nossa maturidade existencial (OLIVEIRA, 2005, p. 220-221).
\end{abstract}

Neste sentido, Santiago não se sente solitário. Na revisão da própria história e na constituição biográfica de seus nobres, o protagonista sedimenta seus valores e sua identidade, em um exercício de conhecer a si mesmo, o que pressupõe a condição de estar só. Desta forma, Santiago apenas vive só e é recluso, mas não parece ser uma pessoa relegada à solidão. Ler e escrever sobre os nobres de várias épocas apontam para a consciência que o protagonista Santiago constrói sobre si.

Neste jogo de espelhos, debruçar-se sobre a construção narrativa dos personagens históricos não revela apenas o outro, o personagem histórico em si, mas o outro na condição de um duplo: aquele que se manifesta em Santiago, que revela os gostos, e desgostos, do protagonista do filme. Neste caso, a solidão aparece enquanto espaço de revelação, enquanto rota para um encontro consigo mesmo (OLIVEIRA, 2005). É a partir dela que Santiago mergulha em seu próprio interior para, aparentemente, retornar à realidade que constrói para si mais resolvido com as coisas do mundo que o cercam.

Estar só é uma resposta à confusão do mundo, ao caos sem domínio das relações sociais fora de casa. Santiago parece não temer a solidão porque ele a acolheu voluntariamente. É possível acreditar que o isolamento de Santiago é o ato que permite a imersão em si, sem distrações ou subterfúgios. O espaço do estar só - a solidão voluntária de Santiago - é um espaço anacrônico. Trata-se do espaço da divagação, da aproximação de Santiago com seus personagens históricos, em que Lucrécia Bórgia encontra Antonio de Pazzi, em que há espaço para a família Visconti e para o Papa Inocêncio III. O Santiago que nos é revelado - fruto do encontro entre a auto-mise-en-scène proposta pelo próprio personagem e a mise-en-scène orquestrada por Salles (COMOLLI, 2008), enquanto realizador - mergulha no passado das festas imponentes na casa do diplomata, banqueiro e empresário Whalter Moreira Salles, pai do diretor do filme. Neste espaço da memória repleta de afetos, Buenos Aires e Rio de Janeiro se encontram.

Mas deve-se trabalhar simultaneamente com outra perspectiva, apesar da ambiguidade por ela instaurada. A de que a reclusão de Santiago, idoso e aposentado, encontra-se perdida na utopia da nobreza e do saudosismo da história. A todo o momento é evocado o que já foi e não é mais. "Tudo era uma beleza, tudo era alegria, encanto, a vida era outra coisa", nos lembra o mordomo. 
No entanto, rastros de sua solidão forçada são deixados em um de seus textos, exibido, narrado e comentado no filme. Rastros que revelam uma solidão distinta daquela proposta pelo personagem em sua auto-mise-en-scène: não como alguém que está só, mas é um ser solitário. Enquanto vemos um plano detalhe fixo da folha datilografada por Santiago, com o título em italiano Scherzo ben sostenuto, que poderíamos traduzir como "Piada bem sustentada" e o texto abaixo escrito em espanhol, ouvimos o narrador ler: "Sonhei que pertencia, somente por um dia, da França à real nobreza. De pronto, acordei assustado... trechos da famosa Marselhesa".

À pequena nota, Salles empreende uma leitura: "Santiago, que podia se imaginar em qualquer época, em qualquer civilização, escolhe sonhar que é nobre durante a Revolução Francesa. Deslocado e fora de lugar até nos sonhos". Enquanto isso, detalhes da forma imperfeita em que a letra foi impressa no papel pela máquina de datilografia nos são revelados. Para logo em seguida acompanharmos um plano geral do portão fechado da Casa da Gávea, justaposto ao do muro com grades em volta da casa, enquanto ele finaliza: "Sua imaginação o levava a um mundo mais antigo e menos moderno, mais europeu e menos sul-americano; a um mundo que julgava melhor. Lutadores de boxe viravam gladiadores romanos; a casa de meu pai, um palácio em Florença".

Santiago refugia-se no passado de sua memória prodigiosa como tábua de salvação de um presente em que ele não cabe. Amigo de fantasmas, entre milhares de páginas escritas e que, segundo ele, fazem-no companhia, Santiago representa outra dimensão da solidão: sua expressão involuntária, representação última do esquecimento social. Dimensão essa decorrente menos de um desejo do que de um processo de exclusão social, quer seja pelo conflito de classes ou pela eventual homossexualidade do protagonista.

\footnotetext{
E, paralelamente, uma outra dimensão de solidão. Aquela mais cruel e estéril, que denota apenas abandono e desamparo, que não gera impulso algum de libertação, nem é, como afirmava Sartre, expressão de nossa admirável condenação à liberdade. Ao contrário, é uma solidão que, como vimos, manifesta a exclusão, a terrível exclusão do seio da sociedade, a triste exclusão do ninho familiar (OLIVEIRA, 2005, p. 225).
}

Neste caso, restam a Santiago, como diria Pais, "recordações embalsamadas no tempo" (2006, p. 147). Coincidentemente, o próprio mordomo faz menção ao ato de embalsamar. No último plano do filme, Santiago narra um diálogo que desenvolveu com o jornaleiro que trabalhava próximo ao prédio em que o protagonista morava. Questionado sobre a filmagem que faziam em sua casa, ele respondeu: "Vão me embalsamar". Santiago tinha (cons)ciência de sua permanência em película, portanto, de que se tornaria memória para outras pessoas. A solidão "civilizada" de Santiago cala 
o sentimento de dor perante as câmeras do filho de seu ex-patrão, cala o sentimento de iminência da própria morte.

\begin{abstract}
Nessa relação entre Salles e Santiago, atravessada pela memória, pelo afeto, pelo poder e pela consciência do escoar do tempo, a mediação última que se instala é entre a evocação da morte ("Estão todos mortos", diz diversas vezes Santiago) e a vida como um devir de que não se pode escapar. Entre o desaparecimento - do próprio Santiago, da mãe e do pai de Salles, da casa da infância - e a luta contra o esquecimento por meio da imagem. (FELDMAN, s.d.)
\end{abstract}

Morte, perda, passado, tempo, história... todas as cinco palavras conclamam sentimento que se manifesta na palavra que só existe em língua portuguesa: saudade; saudade de algo que está ausente, de nobres e aristocratas que já se foram, da casa que jaz fechada, das festas que já terminaram. Ainda assim, seguem existindo na memória de Santiago, a qual ele mesmo define como "prodigiosa". Diz ele sobre sua memória, misturando português, espanhol e italiano, e que aqui tentamos traduzir: "Memória... minha memória querida, que me acompanha, e tomara que assim se faça até a hora da grande partida... da grande partida. E aí vem a frase dos italianos, que dizem: um belo morrer - quem não morre? - por uma vida honrosa" ${ }^{\prime 1}$.

Estar só e ser solitário são condições ambíguas, mas possíveis interpretações sobre a condição do personagem principal, às quais nós, espectadores, temos acesso. A primeira a ser destacada nos aponta para um aspecto positivo de estar só, a possibilidade de manutenção da memória e do confronto com o mundo interior. A segunda aponta para o outro extremo, o aspecto negativo da solidão, da fuga da realidade. Na primeira interpretação, estar só promove o devir, a mudança, a pulsão de vida. O ser solitário, ao contrário, gera a estagnação, o estado de letargia diante da angústia, o desejo do fim.

O caráter reflexivo do filme-ensaio permite que Santiago se estruture a partir dessa dubiedade. Por um lado, a auto-mise-en-scène empreendida pelo protagonista garante um corolário positivo à solidão que lhe faz companhia. Por outro, a mise-enscène minuciosa e rígida conduzida pelo diretor proporciona um efeito negativo ao mesmo sentimento. Por essa via, o filme retira o espectador do seu lugar de conforto e o convoca a assumir um papel crítico e dialógico diante desse cenário, ao propor uma reflexão de difícil solução.

\title{
O espectador: aquele que está só
}

Por volta da metade do filme há uma sequência que revela a postura autoritária do diretor, denunciada pelo próprio Salles ao manter tais imagens no filme. Santiago,

1 No original: "un bel morir - che non si muore? - tutta una vita onora". 
sentado em uma cadeira, apresenta para a câmera o que ele chama de "canto de suas Madonnas": parede da sala do seu apartamento onde estão fixadas, umas sobre as outras, réplicas de imagens da mãe de Cristo, feitas por quatro pintores do Quattrocento. Salles exige que Santiago grave o mesmo depoimento quatro vezes. Ao espectador cabe observar a repetição e com ela perceber que Santiago vai se impacientando com a recorrência, mas faz o que o diretor determina: como se repentinamente estivesse sozinho acompanhando algo a que normalmente não teria acesso. Em outros instantes a mesma sensação reaparece.

O espectador que assiste a Santiago, por essa via, é confrontado com as incertezas diante do que observa: passa a levantar questões, que não são respondidas; pergunta sobre o estatuto das imagens; os lugares de fala do protagonista e do diretor; as relações de poder, observadas como relação entre classes sociais diferentes; a honestidade do cineasta diante de sua confissão; e questiona o contexto da solidão de Santiago.

Sendo assim, o filme sobre Santiago manifesta, em paralelo, a relação estabelecida com o outro. A narrativa é sobre Santiago, mas também sobre Salles e sua posição dentro de sua obra. O longa-metragem tensiona e coloca em questão o estatuto de construção de discursos entre diretor e seu protagonista: em que medida Santiago é quem ele mesmo deseja se mostrar? E em que medida a discursividade do protagonista é modulada pelo diretor? Para além disso, nos questionamos retoricamente: a ambiguidade da solidão que percebemos ao longo do filme, não seria fruto justamente da discrepância que consolida essa relação de poder? Ao espectador, aquele que está só, restam apenas suposições e nenhuma certeza.

Isso acontece pois o filme-ensaio conscientemente constrói a solitária posição do espectador, "em vez de responder a todas as questões que levanta, e entregar um argumento completo e 'fechado', a retórica do ensaio é tal que se abrem problemas, e interroga o espectador" (RASCAROLI, 2009, p. 34, tradução nossa). Nesse sentido, o ensaio convoca o espectador a envolver-se de forma individual com a obra, e assim traçar um processo reflexivo singular sobre o mesmo assunto, sem a garantia de que enunciador e espectador cheguem a qualquer conclusão, muito menos à mesma. O filme-ensaio nos induz, enquanto espectadores, a um estado de solidão que permite refletir sobre nós mesmos e os outros, por meio de um encontro experiencial particular com a obra.

Ao passo que reconhecemos, em Santiago, a existência de um personagem que se apresenta como alguém que está só e é exposto como um ser solitário, somos capazes de identificar o estado de solidão, por mais que compartilhada, que a sala de cinema nos impõe enquanto complexificamos acerca da possibilidade da nossa própria solidão ser mais que um estado passageiro no mundo social. 


\section{O ensaísta Salles: do trânsito entre o estar só e ser solitário}

Salles vive a experiência de ordenar o sentido de seu material durante a montagem. Desta forma, o diretor vai ao encontro de Giannetti (1975) quando admite que Santiago se trata de um filme movido por sua paixão, mas também pela sua relação com o material. Em determinado momento, vemos planos fixos registrados dentro e fora da casa da Gávea, onde o cineasta morou quando criança: folhas caem na piscina; cabides pendurados no varal balançam ao vento; móveis da casa aparecem cobertos com panos brancos; o mesmo plano surge com móveis descobertos; um lutador de boxe aparece com suor escorrendo, em close; um trem de brinquedo passa correndo no escuro... O narrador questiona se as folhas caíram ao acaso no momento da filmagem. O vento balançou os cabides? As cadeiras foram deixadas mesmo com o pano branco? O suor do boxeador era maquiagem? Ao final da sequência, diz: "Assistindo ao material bruto, fica claro que tudo deve ser visto com uma certa desconfiança".

Se tudo deve ser visto com certa desconfiança, talvez pudéssemos questionar, entre outras coisas, o interesse do cineasta pela temática da solidão que é transversal ao filme e materializada na figura do protagonista Santiago. Salles parece testar os limites da solidão e nostalgia de sua própria subjetividade por meio dos encontros com o ex-mordomo da família, tomando por resultado um discurso que revela o sentimento da solidão - não apenas de Santiago, mas também de si - por meio de uma ambiguidade reflexiva: vive-se um trânsito permanente entre o estar só e o ser solitário.

E essa experiência do realizador se dá por meio de "uma consciência ativa e assertiva que se testa, desfaz ou recria por meio da experiência, incluindo as experiências da memória, do argumento, do desejo ativo e do pensamento reflexivo" (CORRIGAN, 2015, p. 34). O sujeito ensaístico, assim, mais do que produzir expressões, converte-se em produto de expressões da experiência.

Isto é: em Santiago, é necessário que o realizador dê espaço para que o protagonista enuncie a si mesmo como alguém que está só, aproxime-se dele e reconheça essa noção, por dividir com o personagem essa sensação, enquanto Salles voluntariamente se torna recluso para refletir sobre o filme que realiza. Para logo em seguida refutá-la e insinuar, quando não declarar, que não se trata de um estado de Santiago, mas de um ser solitário, por perceber que a relação mantida com o ex-mordomo sinaliza para uma exclusão social que jamais deixou de existir, enquanto o ensaísta pode estar rodeado por pessoas que conhece e, por meio da experiência, ainda compartilhar com ele sentimentos de profunda solidão. Afinal, a "solidão não é apenas uma realidade individual. O seu significado não é independente dos contornos sociais em que é vivida. O próprio medo da solidão é um medo social" (PAIS, 2006, p. 351). 
É sabido que a obra surge da relação de Salles com o seu material filmado 13 anos antes. O projeto inicial não funcionava a contento porque Salles não se projetava dentro dele. A tomada de consciência de si permitiu, ainda, o seu julgamento pessoal dentro do processo intrínseco às filmagens.

Isso pois a escrita do ensaio não registra a experiência, mas é a própria experiência revelada no ato de escrever. Trata-se da escrita da experiência que se dá na experiência da escrita. Porém, é necessário um alerta. Não se trata de uma escrita autobiográfica, em uma narrativa de sucessão de eventos ou percursos, sob efeito de ordenação. O ensaio, antes, registra impressões, cogitações, em um processo que pressupõe a multiplicidade do sujeito da escrita e a sua contrariedade. Desta feita, o eu da escrita se constrói como sujeito e objeto do ato de escrever. Não se trata do ato de descrever uma consciência, mas uma consciência que descreve alguma coisa. Esta articulação é fruto de um elemento presente no ensaio literário: a objetividade de (re)conhecimento do mundo articulada com a subjetividade reflexiva de quem escreve o filme.

Tal tomada de consciência, que se experimenta e reinventa, surge em Santiago após o distanciamento do material, e à posterior primeira experiência de montagem. Em entrevista realizada em 2017, Salles explicou este processo.

No filme que eu rodei em 92 ou 93, e que eu tentei montar - e não consegui, fracassei na montagem - eu não existia, era só ele [Santiago]. [...] E o espectador não sabia o que estava por trás da fala dele. O que estava por trás da fala dele era eu dirigindo ele, era eu dizendo como ele devia falar, o que que ele devia falar, enfim... tinha afeto, tinha carinho, tinha amor, mas também tinha classe, também tinha o fato de eu ser filho do patrão e ele ser o funcionário de meu pai. Essas coisas não eram parte do filme e, portanto, o filme resultava em uma coisa muito artificial. Eu não sabia porque não funcionava, mas eu sabia que não funcionava. E aí, revendo o material, eu me dei conta de que a única maneira desse filme poder existir era se eu explicitasse a natureza dessa relação que se estabeleceu durante a filmagem, me tornando personagem (CONVERSA COM BIAL, 2017, 7:05 - 8:05).

Santiago admite sua feição de ensaio na medida em que é indivisível do seu processo fílmico, na medida em que o "raciocínio do ensaísta obriga-o a uma intensidade maior que a do pensamento discursivo, porque o ensaio não procede cega e automaticamente como este, mas sim precisa a todo instante refletir sobre si mesmo". (ADORNO, 2003, p. 44). A relação que Salles estabelece no ato de filmar com Santiago, revivida ao longo dos próximos anos pela tentativa de adensar o pensamento em linguagem audiovisual articulada por meio da montagem, permite a ele o debate sobre sua relação com as imagens, sobre as especificidades do seu próprio cinema e sobre a solidão que o(s) atravessa $(m)$, pensada a partir do lugar 
social que cada um deles ocupa e das relações possíveis entre eles. O ato criador é, sobretudo, um ato solitário. Refletir é um ato solitário, que envolve o conhecimento intelectual sobre o que se enuncia, bem como sobre a linguagem que se emprega.

Em determinado momento ouvimos por meio da voz-over que Santiago gostava de dançar. "Uma das boas lembranças que eu e meus irmãos guardamos de nossa infância é Santiago tocando castanholas ao som de uma música que nós não conhecíamos, mas que certamente não era espanhola. Nunca nos esqueceremos disso". A narração começa em um plano anterior, continua em fade out na imagem, até que vemos entre uma cortina e uma parede, ao fundo dentro de uma sala, em plano americano com o corpo virado de lado, Santiago tocando o pequeno instrumento de percussão, ao som de uma música clássica e dançando solitariamente. Aqui a sensação que se tem é de uma escolha pelo estado de solidão, em que dançar sozinho representa o prazer de desfrutar de sua própria companhia. Como se, nesse instante, Salles permitisse que a auto-mise-en-scène de Santiago se desenvolvesse um pouco a ponto de dar os contornos desejados à sua própria imagem.

Em seguida, o narrador nos explica que Santiago gostava do ator e dançarino Fred Astaire, personagem de suas anotações na categoria "Artistas do cinema mudo, sonoro e falado". Após vermos Santiago bailando, bem mais à frente, assistimos um número de dança de Astaire e Cyd Charisse em A roda da fortuna (Vincente Minnelli, 1953), o filme preferido de Santiago, a segunda e última sequência em cores do filme. Nela, os dois dançam juntos e em perfeita harmonia, dividindo o tempo e o espaço embalados pelo mesmo ritmo. Revelar que este é o filme preferido de Santiago ao passo que incorpora a sequência integralmente como material de arquivo ao filmeensaio, contrapõe as duas cenas de dança. Aqui, é a mise-en-scène de Salles que aparenta tornar evidente a percepção que possui da maneira como Santiago se vê. Para o diretor, em alguma medida, Santiago mais que desfrutar de sua própria companhia, fantasia em sua profunda solidão fazer parte de contextos que nunca lhe pertenceram. Santiago e Fred Astaire dançam no mesmo filme. No entanto, estão separados, entre outros aspectos, por mais de 30 minutos de duração.

Para se fazer ensaio, o diretor de Santiago deve manipular a imagem, tratá-la "como uma segunda camada; é preciso criar um espaço, uma distância para voltar a olhá-la. Isso se pode conseguir com a mediação da voz; mas essa distância também se estabelece de forma natural ao se trabalhar com imagens alheias" (WEINRICHTER, 2015, p. 65). É nesse sentido que Salles assume um estar só reflexivo: por intermédio da voz-over, que programa e dá ordem à experiência; e das imagens que, embora tenham sido geradas por ele, comportam-se como imagens alheias dada a distância temporal que os separa. É a voz-over e a livre associação das imagens, fruto de preciso trabalho de montagem, que sugere a associação do prazer de Santiago em dançar e seu filme favorito. Isso é feito ao mesmo tempo em que gera o contraponto 
entre estar acompanhado, em A roda da fortuna; e ser solitário, em Santiago, apesar da dança e das castanholas.

No cristianismo antigo, anacoretas e cenobitas viviam imersos em silêncio contemplativo e devoção. Estar só, neste caso, não é gerador de solidão. Os cenobitas (cujo nome deriva do grego koenóbion, "lugar onde se vive em comum") rompiam o silêncio no momento de uma refeição coletiva, batizada por eles de communicatio (tomar a refeição da noite em comum). Este termo gera o conceito "comunicação" (MARTINO, 2001), que pressupõe uma ruptura de isolamento, um estar com o outro, a enunciação de algo em estado de consciência. No filme-ensaio, a solidão não é apenas um sentimento privado, fruto de alguém isolado, mas, sendo cinema, a solidão é comunicada. Em Santiago, o ensaísta Salles a comunica com certo tom de melancolia, como aquele que, por sua própria ótica, reconhece ter experimentado o trânsito entre sua condição reflexiva e privilegiada de estar só, e a natureza nostálgica e desfavorecida de ser solitário do protagonista Santiago.

\section{Algumas palavras antes do fim: da solidão à solitude}

Há o instante em que a alegria é revelada: a família Moreira Salles toma banho de piscina em sua mansão na Gávea, num fragmento colorido de filme em formato Super-8. Nas imagens, é possível ver o patriarca brincando com os filhos dentro d'água, junto de sua esposa. Do lado de fora, uma das babás uniformizadas leva uma das crianças, enquanto outra babá aproxima o carrinho de bebê da área da piscina. Neste momento, a parte musical da sequência dá lugar, em fade out, ao silêncio.

Existe uma possível simetria entre o preto e branco sonoro, de todo o filme; e as únicas imagens da família, coloridas e silenciosas. É como se a falta de som ou de cor evocasse a melancolia da própria falta sentida pelo diretor. O passado está presente, mas não é o presente. A família, no passado, em cores, não soa mais. Santiago, o personagem, no tempo presente do filme, em preto e branco, narra o que já foi.

Os usos do som, e do silêncio, em filmes-ensaio produzem uma tensão não apenas no que está em quadro e no fora de quadro, mas também no real e no imaginário. Possuem uma linha própria ligando os espaços ao que não está projetado - isso nos permite ouvir um "outro lugar". Este "outro lugar" está localizado fora do domínio do discurso (ALTER, 2011).

Na concepção do filme-ensaio, Salles precisou se afastar do material de origem para se reaproximar dele, para ser capaz de ver e ouvir esse "outro lugar", no que pode ser definido como um processo de maturação. Tomar essa distância reflexiva para aos poucos imergir no pensamento-filme e mergulhar em seu processo, exige um perder-se solitário em si mesmo. Este caminho foi percorrido por Salles ao longo de 13 anos. Este processo reflexivo deu corpo ao filme, ao personagem e às relações 
entre os personagens; ao passo que desenhou o Santiago Badariotti Merlo que nos é revelado, pelo encontro da auto-mise-en-scène de um e da mise-en-scène de outro. O Santiago cuja condição ambígua de solidão nos é apresentada.

Santiago é recluso, retoma o passado como quem revira o tempo ao avesso. O protagonista do filme de Salles é alguém que prefere conviver entre anotações sobre personagens históricos em um tempo suspenso. O filme cria um tempo-solidão identificável e enunciado, em um contexto em que Santiago procura o isolamento para encontrar-se, ou, ao contrário, mergulha no isolamento para esquecer-se.

Nós, espectadores inertes e solitários, somos conclamados a pensar sobre as relações interpessoais constituídas por João e Santiago, sobre uma vida permeada pela solidão, que ora é autêntica e ora é sonhada. Nós, espectadores, somos conclamados a pensar sobre a solidão, que transcende o filme e seu personagem; e a apontamos para o espaço que ocupa no "fazer o filme" e seu diretor. O filme se pensa como filme, enquanto Salles reflete sobre seu personagem, sobre si e a solidão que os transpassa.

A Santiago, talvez, caiba ambiguamente estar só, ao mesmo tempo em que se é solitário. Ao espectador compete estar só junto à obra, como um voyeur da solidão alheia, agora compartilhada. A Salles toca colocar à prova sua própria relação com a solidão, por meio da experiência reflexiva com Santiago, para sugerir a contínua impermanência que vivenciamos entre o estar só e o ser solitário, entre a solitude e a solidão.

Rafael de Almeida é professor do curso de Cinema e Audiovisual da Universidade Estadual de Goiás - UEG. É doutor em Multimeios pela Universidade Estadual de Campinas - Unicamp.

rafaeldealmeidaborges@gmail.com

Paulo Passos de Oliveira é doutorando em Arte e Cultura Visual pela Universidade Federal de Goiás - UFG. É mestre em Comunicação pela Universidade Federal do Rio de Janeiro - UFRJ.

paulopassosdeoliveira@gmail.com

\section{Referências}

A RODA da fortuna (THE BAND Wagon). Roteiro: Adolph Green; Betty Comden. Direção: Vincente Minnelli. Comédia/Musical/Romance. EUA: 1953. 112min. Vídeo digital, color.

ADORNO, T. O ensaio como forma. In: Notas de literatura. São Paulo: Duas Cidades/Editora 34, 2003, p. 15-45. 
ALTER, N. Sound thoughts: hearing the essay. In: KRAMER; TODE. Der essayfilm: ästhetik und aktualität. UVK Verlag, Konstanz, 2011.

COMOLLI, J. Ver e poder: a inocência perdida - cinema, televisão, ficção, documentário. Belo Horizonte: Editora UFMG, 2008.

CONVERSA com Bial. Entrevista com João Moreira Salles. Rede Globo de Televisão. Brasil, 08/11/2017. 40:19min. HD, color. Disponível em: <https://www.youtube.com/watch?v=oYJ9Gl0outw>. Acesso em: 26/11/2017.

CORRIGAN, T. Sobre o cinema e o ensaístico. In: O filme-ensaio: Desde Montaigne e depois de Marker. Campinas, SP: Papirus, 2015.

FELDMAN, I. Santiago sob suspeita. Revista Trópico. s/d. In: <http://www.revistatropico.com.br/ tropico/html/textos/2907,1.shl>. Acesso em: 02/08/2016.

GIANNETTI, L. D. Godard and Others: Essays on Film Form. Rutherford, N.J.: Associated University Press, 1975.

MARTINO, L. C. De qual comunicação estamos falando? In: HOHLFELDT, Antonio; MARTINO, Lu. C.; FRANÇA, Vera Veiga. (Orgs.). Teorias da Comunicação: conceitos, escolas e tendências. Petrópolis, RJ: Vozes, 2001, p. 11-25.

OLIVEIRA, J. F. P. Fundamentando o conceito de solidão. In: PACHECO, J.L. [et al.] (Org.). Tempo: rio que arrebata. Holambra, SP: Ed. Setembro, 2005, p. 219-226.

PAIS, J. M. Nos Rastos da Solidão: deambulações sociológicas. Porto: Âmbar, 2006.

RASCAROLI, L. The essay film: problems, definitions and textual commitments. In: The personal camera: subjective cinema and the essay film. New York: Wallflower Press, 2009.

SANTIAGO. Roteiro e Direção: João Moreira Salles. Documentário. Brasil: 2007. 80min. Vídeo digital, P\&B.

WEINRICHTER, A. Um conceito fugidio: notas sobre o filme-ensaio. In: TEIXEIRA, Francisco Elinaldo. O ensaio no cinema: formação de um quarto domínio das imagens na cultura audiovisual contemporânea. São Paulo: Hucitec, 2015. 